\title{
The role of measurement in the development of industrial automation
}

\author{
S.S. Carlisle \\ United Kingdom
}

This is a reissue of a paper which appeared in ACTA IMEKO 1967, Proceedings of the $4^{\text {th }}$ International Measurement Congress, 1967, Warsaw, vol. 1, pp. 37-50.

The paper sets a frame on the role of measurement and control as critical tools to support the automation of manufacturing processes. In this perspective three main requirements for measurement are discussed, i.e., to identify where automation can be most profitably used; to investigate individual process behaviors and hence to formulate process control strategies; and finally to perform quality control of products.

\begin{abstract}
Section: RESEARCH PAPER
Keywords: industrial automation

Citation: S.S. Carlisle, The role of measurement in the development of industrial automation, Acta IMEKO, vol. 3, no. 1, article 3, May 2014, identifier: IMEKO-ACTA-03 (2014)-01-03

Editor: Luca Mari, Università Carlo Cattaneo

Received May $1^{\text {st }}, 2014$; In final form May $1^{\text {st }}, 2014$; Published May 2014

Copyright: (C) 2014 IMEKO. This is an open-access article distributed under the terms of the Creative Commons Attribution 3.0 License, which permits unrestricted use, distribution, and reproduction in any medium, provided the original author and source are credited
\end{abstract}

\section{INTRODUCTION}

Throughout the whole history of scientific endeavour the science and technology of measurement has been of paramount importance. Our knowledge of physics, chemistry, the nature of matter and of human life itself has progressed according to our ability to measure and so to test our theories. Furthermore, it is by measurement that we can communicate experience from one research centre to another; thus a facility is provided for research work to be continued by one worker following another. It also allows workers in different locations to coordinate their efforts in the advancement of scientific knowledge. More recently, measurement in industry has enabled manufacturing and processing skills to be more readily communicated from one worker to another; such communication means that advances in manufacturing practice can proceed and spread more quickly throughout an industry. When operator skill has established optimum conditions for working a process, the instrumentation of the process enables these best conditions to be easily transferred to other operators on similar processes without repeating the work. Recent experience by a firm starting up a new oxygen-blown steelmaking process showed that comprehensive instrumentation and data logging on the plant resulted in the commissioning time to get the furnace up to its target production rate being greatly reduced. It is only by measurement in industry that we can really know the efficiency of utilisation of materials and of machines or processes. It is, thus, an essential basis upon which to advance our productivity.

Measurements are, of course, only of value if we use the results. In basic research we use them to confirm or improve the theory we are testing. In industry we use them, or should use them to alter our production planning or our plant operating conditions to achieve a better result, either as regards productivity or product quality. Of course, if we do not use our measurements in industry to test out and compare alternative, and possibly better ways of doing things, we are wasting a valuable facility.

Measurement combined with human intelligence in interpreting the result and a will to take the action prescribed can hold a process at a constant best working condition in spite of inevitable disturbances in input conditions. When the interpretation of the measurement is simple and the control action easily defined we have for many years now been able to dispense with human interpretation and apply automatic control as in single variable feed-back control systems. Nowadays, with the facility of analogue and digital computers we can perform more complex interpretation or processing of the measurement information and determine the required control action automatically in circumstances where previously 
we had to employ human judgment and skill. By automation I mean the automatic determination of control action according to measurement information. It is only a matter of degree as to whether a digital computer is involved or not in the processing of the information.

Measurement science and technology is undoubtedly of importance on its own. I believe that it is by its use in the implementation of automation that it becomes of such unusual significance to industry - and, indeed, to our whole way of life.

It is becoming realised in every progressive country that the standard of living prevailing in a community is closely related to the productivity of that community. By productivity, I mean the quantity of a consumable or durable product (such as a can of beans, a motor car), or of a service, such as a telephone connection, that can be produced for a given input of all resources including fuel, raw material, human effort and capital investment. By mechanisation and the use of massive machines, like continuous strip rolling mills, we can produce enormous quantities of steel strip per unit human operator employed. Of course in such applications there is a large resource input in the form of fuel and capital investment in machines which basically are produced by human effort. It is important to realise that when discussing productivity we are concerned with output as a function of total resource input, not just output per man on a machine.

It is this ratio of output to total resource input which directly determines a national standard of living. It is this ratio which automation can optimise. It is the job of automation to ensure that fuel is efficiently used in a process by applying automatic control to process variables. It is also its job to control raw material conditions and process conditions to ensure that there is a maximum yield of saleable product. Furthermore, automation can be used to optimise production planning so that at any time all the components of a production facility are used best in meeting the requirements of the order book at that time. Minimisation of inter-process stock is of course an important part of this exercise.

The point I wish to emphasise is that automation is concerned with the optimisation of operation of a complete manufacturing complex and not just with providing automatic control of processes nor just with minimising the labour utilisation on operation of a particular plant. It therefore follows that the use of automation in industry is a major controlling factor on our standard of living.

\section{IMPEDIMENT TO PROGRESS IN USE OF AUTOMATION IN INDUSTRY}

If one accepts the great significance of this technology to any progressive country, and I think the leaders of nations do, and one notes the outpourings of technological achievement on measurement, automatic process control and computer data processing, which come from conferences like this and IFAC and many others, one might well ask: "Why don't we all get on more quickly in using this wonderful tool?" I believe that in general technologically advanced countries find themselves in tile position that their technical competence in automation is taken advantage of by far too small a proportion of their total manufacturing industry. The shining examples of achievement in industries like steel, petro-chemicals, paper production, aircraft and traffic control, get much discussed. But what about automation in food production, brick-making, pottery manufacture, timber products and in the multitude of light engineering industries? These are the industries which in nearly every country are the greatest employers of labour and usually the more backward technically. Why are they not so eager to exploit automation?

There are many reasons of course. The more obvious ones which get much discussed arise from sociological and capital investment considerations. A less obvious reason but one which I think is far more important and much neglected arises from the fact that automation, more than any other technology, requires a close coordination of effort by people of many different skills and disciplines if it is to be successfully employed. The control engineer cannot make any progress in selling his technology to the building brick manufacturer unless both parties take the trouble to learn something of each other's business. Their disciplines, expertise and language are vastly different and yet it is only by working together that success will be achieved. Many of you will have had experience of instruments which you developed for use in an industry - and which you felt confident from trials were satisfactory technically - and yet they fell into disuse by the firm which originally requested them. The reason probably was that in your enthusiasm for technological development of the device you neglected to formulate and communicate to the management of the company a proper conception of the use of the device as a means of improving the productivity and profitability of his business.

It is noteworthy that in industries such as steel and modern chemicals, where measurement and control engineers have been introduced alongside production managers, process technologists and plant designers, there have been the most significant developments in the use of automation. This suggests that the use of automation has to be stimulated from within an industry. It cannot be applied by edict or exhortation from outside. The basic problem is one of making those who know the process and product technology of their industry also conscious of the new technology of automation and the use that can be made of it. Similarly, the control engineer must learn something of the business and processes of the user industry before he can offer his technology as a viable proposition.

I believe that measurement and control engineers must take a share of the blame for too slow progress in the wider use of this technology in industry. Research and development people concerned with measurement and control technology too often grasp problems which industry puts to them because the problem gives them an opportunity to extend their research and development expertise. It would be better if their primary motivation was to advance the interests of the user by solving his problem rather than to advance their own disciplines. In other words, we require more research and development people whose enthusiasm is to solve real industrial control problems rather than to develop solutions and then seek problems to justify the solutions.

\section{THE ADVANCEMENT OF THE USE OF AUTOMATION IN THE UK}

Taking account of these problems which I have outlined, special facilities have been developed in the UK to promote the wider use of automation throughout our industry [1]. Special attention is given to the less technically advanced industries and to the medium to small sized firms. I should like to describe these facilities and some examples of projects undertaken 
because they demonstrate the role of measurement in promoting industrial automation.

In the UK we have a network of 49 Research Associations, the majority of them serving process industries such as food, baking, textiles, paper manufacture, printing, furniture-making, steelmaking, etc. Their job is to advance the technology of the industries they serve. They provide centres of knowledge of their industries' process and product technology and its trends of development. The procedure now is to form within each of these Research Associations groups of measurement and control technologists who will develop within the particular industries they serve more technical awareness about control technology. A few of the Research Associations already have automation groups within their organisations. For example, the British Iron and Steel Research Association has a large operational research and control engineering department and has done much to advance automation in the steel industry. To aid the development of this procedure one of tile research associations, the Scientific Instrument Research Association (SIRA) has been appointed as the focal point for development of this automation activity throughout the Research Associations. SIRA now has within its organisation a strong industrial measurement and control division which encompasses work on industrial instrument development, control engineering and operational research. We believe that there is special advantage in having a systems engineering expertise in all organisation otherwise concentrated on measurement research and development. It is through industrial systems studies that the requirements for instrument development can be defined most reliably. I think it is wrong to isolate instrument research and development from systems and control engineering.

The method of working which has been evolved is to form a joint team of control engineers from SIRA with experts from the other Research Association and arrange for this joint team to make a systems study in a factory of the particular industry. The job of the joint team is to study the whole manufacturing complex, the economics and technology of its operation, and out of this study to formulate proposals for the ways ill which automation can be introduced so as to be of greatest advantage in improving productivity. Arrangements can then be made to install measurement and control systems to demonstrate economic and technical feasibility. All this work is done in close collaboration with staff of the particular firm chosen for the study. A vital feature in the carrying out of these studies is that control engineers, process technologists and works production staff are united in conducting the operation.

\section{THE ROLE OF MEASUREMENT IN ADVANCING AUTOMATION}

The first objective in these production system studies is to acquire data on production performance, plant utilisation and process yields in order to ascertain what parts of tile whole production process can benefit most from improved control. Too often one is hampered in conducting these operation studies by the inadequacy of measurement of such things as machine operating time, inter-process stock levels, scrap losses at each process etc. When such matters are studied the opportunities to improve production practice by automation often become apparent and the economic justification can be assessed. For example, in an initial study we made of a biscuit production plant some 18 months ago, the following observations were made [2].

1. One dough mixer was used to feed each biscuit production line so resulting in a system of 7 mixers feeding 7 lines. The mixers are batch operated and quite separable from the biscuit lines which are continuous flow processes. It was observed that the mixer utilisation was only about $20-50 \%$ of their total capacity when keeping all biscuit lines busy. It was thus apparent that by more precise scheduling and control of mixer operation - such as can be done by a computer (parttime use) - the number of mixers could be reduced from 7 to 4 with a potential saving in capital investment of about $f, 60,000$.

2. Some defective biscuits are produced at each stage in the process, e.g. due to faulty dough mixing, malfunctioning of the dough sheeter or the cutters and disturbances in oven operation. Also variation of biscuit dimensions causes packaging machine failures and consequent rejection of biscuits. The total production of defectives was estimated to be about $2.5 \%$ of production. A reduction of this by say $1 \%$ would be worth $f, 15,000$ per annum.

3. Biscuit packages are sold to a specified weight and it is legally necessary that this weight be supplied as a minimum. Thus, because of a random variation in individual biscuit weights the average package weight is greater than the weight specified. This excess is known as "give-away" and can be as high as $6-7 \%$ (6-10 drams per packet). This can be reduced by reducing the variance in biscuit weight and it is calculated that for each dram reduction in give-away per packet there is a saving to the company of $f, 75$ per ton of biscuit production. In a typical plant a reduction in give-away of 1.5 drams per packet is worth $\mathcal{f}, 20,000$ per annum to the company.

These observations stimulated the development of several in-process measuring devices and control systems. It was apparent that the manual method of sampling biscuits and measuring their weight and dimension by traditional means was unreliable and tedious. Furthermore, the making of these measurements was clearly necessary to improve supervision and to give a basis for automatic control of the biscuit machine. Consequently a device was developed for automatically sampling the biscuits as they emerge from the baking oven on a belt [3].

Figure 1 shows this sampler. It picks up a stream of biscuits from the moving belt and measures their thickness, weight, ovality and colour (brownness) and puts the information through a data logger on to punched tape, while returning the measured biscuits on to the belt in the same place from which they were removed but some distance downstream.

Some hundreds of thousands of biscuits have been sampled through this machine and distribution curves of weight and dimension variance obtained by computer analysis of the data logger output. The immediate value of this sampler is to show how well or badly a biscuit line is behaving and to enable the effect of changes in process operation to he measured. It will also show the improvement in thickness and weight variation which we expect to get from an automatic thickness control system now being installed on the dough sheeter. Ultimately, it will be the master instrument for supervision of several automatic process control systems to be installed on the dough sheeter and on the baking oven. 
In a similar way we have made a study of a ceramic tilemaking plant which produces some $150,000 \mathrm{sq}$ yds of glazed tiles per week. Because of the variability of material, and process parameters, there is considerable production of defective tiles at each stage of the process which includes making green tiles from the clay mix, firing of the tiles and glazing. The percentage of defectives at each stage varies from $5-7 \%$ and a rough estimate of the total cost of defectives is about $£ 180,000$ per annum or about $7 \%$ of production costs. Even a reduction in defectives of only one-quarter of the present value would be worth about $f$ 45,000 per annum. Assuming a $25 \%$ per annum return on capital invested is required, this can justify a capital cost for measurement and control apparatus of $f 180,000$. Work is now being done to reduce defective production by better control of clay composition, by control of the presses and kilns and by inprocess measurement of the tile dimensions, shape and surface quality. A system for automatic control of the moisture content in clay dust is being developed and it is estimated that this will reduce the cracking of the tiles during firing and bring about a saving of $£ 11,000$ per annum.

So we see that a first requirement for measurement is to ascertain what a production system is doing and so to identify where automation can be most profitably used.

The next function of industrial instrumentation is to investigate individual process behaviour and determine the most significant variables and hence formulate a process control strategy. This is the function which has had most attention from control engineers and leads to the sort of process instrumentation and control familiar to us all. The thickness measurement and control of the biscuit dough sheet I referred to earlier is a typical example in this category. It is surprisingly similar to the problem of automatic thickness control in steel rolling mills. I would like to mention a few more unusual examples in this category each of which I think has a message to give.

In the manufacture of fan blades for motor car engines the blades are spot welded on to a hub flange and it is common practice to do destructive examination of the welds of a sample of fans taken from the production line. This is wasteful and does not ensure that no defectives get through. In searching for a non-destructive test the British Welding Research Association made a detailed study of the resistance spot welding process and found that while the weld is being made the electrodes are forced apart about ten thousands of an inch and then return as the molten nugget of metal is formed between the parts being welded [4]. Figure 2. shows curves of separation of the electrodes for a splash weld with too solid heating $(\mathrm{H})$, a good weld $(\mathrm{N})$, and a weak weld with too little heating $(\mathrm{L})$.

It was observed that this curve had a particular form when a good weld was made. Thus, it became possible to inspect a weld while it was being made by measuring the time taken for a particular magnitude of electrode separation to occur. This principle is now employed in a resistance weld inspection device which has been developed as an attachment to a welding machine. Work is now proceeding to use tile principle as a base for automatic control of the resistance welding process.

Consider another example. In the manufacture of clay bricks the brick is formed by extruding clay into the required section and then cutting up into bricks ready for firing. It is important that the moisture content of the clay be consistent so as to obtain a uniform contraction of the brick during firing and so reduce incidence of cracking and deformation. For some

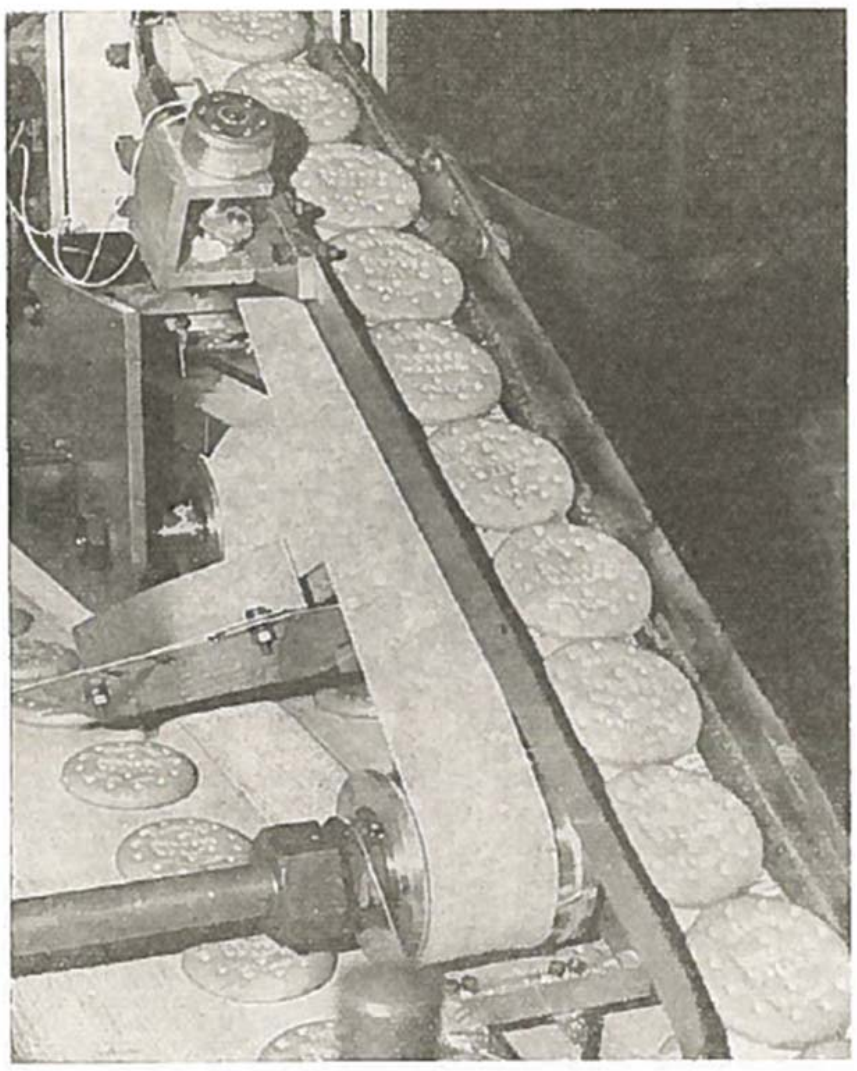

Figure 1. Automatic sampling machine installed on a biscuit line.

time a method of measuring the moisture content of the clay has been sought but no really satisfactory solution found. Some studies of the extrusion process were made by the Ceramics Research Association and these showed that a measurement of back pressure behind the nozzle of tile extruder is a very good and consistent measure of tile moisture content of the clay. Pressure is easy to measure with rugged apparatus suitable for a brick works. This has now been developed as a system for automatic control of the moisture content in tile clay mix. This is a much simpler solution than trying to measure true moisture content.

These two simple examples illustrate the need for study of the technology of an industrial process to precede development of process instrumentation and control. They emphasise the responsibility that rests on the control engineer to familiarise himself with the technicalities and mode of operation of a manufacturing process before he applies his specialist technology. Failure to recognise these requirements can result in valuable effort being applied to development of the wrong instrument for control of a process.

A third function of industrial instrumentation which is of

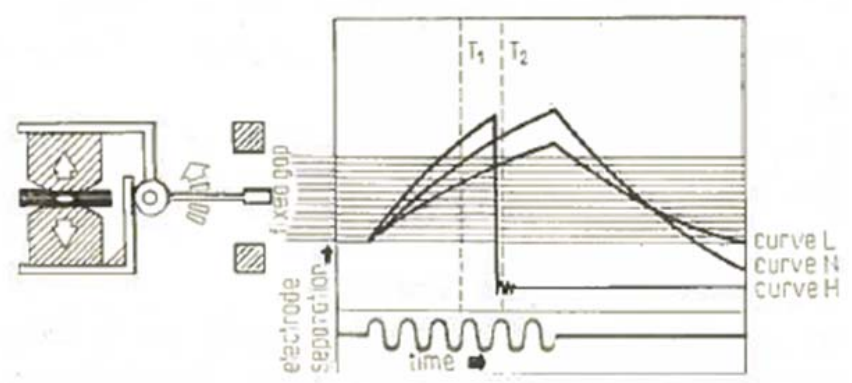

Figure 2. Principle of operation of weld monitor. 
rapidly growing importance is measurement or inspection of a product, either during the production process or on completion. The need for this can arise for a number of reasons.

1. To remove a limit imposed on production by shortage of labour for product inspection.

2. To provide faster detection of defective product made and so facilitate quicker correction of a faulty process and provide a basis for automatic process control.

3. To detect and remove from a sequence of processes a partially completed product which is defective and which may waste or damage the succeeding process if it is allowed to proceed.

4. To improve quality control of products.

Very often the inspection of components or products in a factory is one of the most labour intensive functions and is often a tedious and onerous task. Consider for example the manufacture of metal coins which in most countries are high precision and high quality objects. It is common practice to inspect visually the blanks coming from the stamping machine to prevent defective blanks being fed to the coining presses where they may cause damage to expensive dies. A coinage plant may produce 20 million coins per week and one will usually find a team of 20 or more inspectors looking at blanks on a moving belt to detect any defectives. This task of visual inspection becomes increasingly expensive as labour pay rates rise and recruitment of suitable labour becomes increasingly difficult. This is an ideal task for the automatic inspection instrument and recently SIRA has developed a photoelectric device which will inspect the blanks at a speed of up to 40 per second and reject those which have a damaged edge or are out of tolerance on size. Figure 3 shows the instrument. The coin blank is passed over an illuminated aperture behind which is an optical system which casts an image of the blank on a photocell. This photocell has a cathode consisting of four quadrants. If this blank is truly symmetrical with no edge damage there will be during the transit of the image over the four photocell quadrants some point at which there is a balance of photo currents in opposing quadrants. This balance point is detected electronically. If no balance is found due to a damaged edge the coin is rejected. This principle may be applied to check dimensions and shape of any two dimensional symmetrical objects.

Another interesting in-process inspection problem arises in the manufacture of glazed ceramic tiles. After firing the tiles are passed to the glazing plant. Some of the defects on the glazed tiles can be attributed to surface defects on the uncoated tile and if these could be detected and rejected by a machine before glazing there could be a significant saving on production costs by avoiding the glazing of defective material. An apparatus is under development for this purpose. It is also aimed at replacing the large labour force required to inspect the finished tiles.

Numerous new requirements for automatic inspection are introduced as a result of progress in automation of assembly, packaging and filling operations. For example, the introduction of automatic filling machinery in the pharmaceutical industry to put drugs into vials, calls for much closer tolerances to be maintained on the vial dimensions, and so the need arises for automatic dimension checking of the empty vials. Furthermore, when the filled vials are packed by machine into cartons these need to be inspected automatically for misfills or particulate matter in the filling. Such inspection is done by the human packer as a simultaneous task, but when he or she is replaced by the packaging machine, automatic inspection becomes necessary. This situation arises in many different industries. While packing wrapped confectionery products into cartons the human packer simultaneously checks the quality of the product wrap. However, when the machine does this packing a device for checking the wrap must be introduced.

Automatic assembly of a wide range of engineering products like watches, gear boxes, electricity meters, electric motors, cycle wheels etc. is being introduced [5]. This is going to impose much stricter discipline on component dimensions and quality and will make objective inspection of components essential. In the simple case of introducing automatic bottle capping machines it becomes necessary to inspect and control the dimensions of the bottle necks and tops much more precisely than is required with manual capping. An automatic assembly machine putting screws in must be protected from being fed with screws without slots in the head.

Automatic inspection of such things as the surface of tinplate or metal foil or paper presents interesting problems because the decision of acceptance or rejection depends on a judgment which has to take into account the type, size and distribution of defects. Detection of the defects is not usually difficult with available technology, and at the high production speeds now common with these materials. The real problems lie in processing the signals from the defect detectors so as to make decisions automatically on suitability or otherwise for the particular use for which the product is required. For this problem we hope to get help from those working on pattern recognition techniques.

Another problem of product inspection which I think is of great potential interest is in checking items produced in large quantities such as postage stamps, currency notes or similar

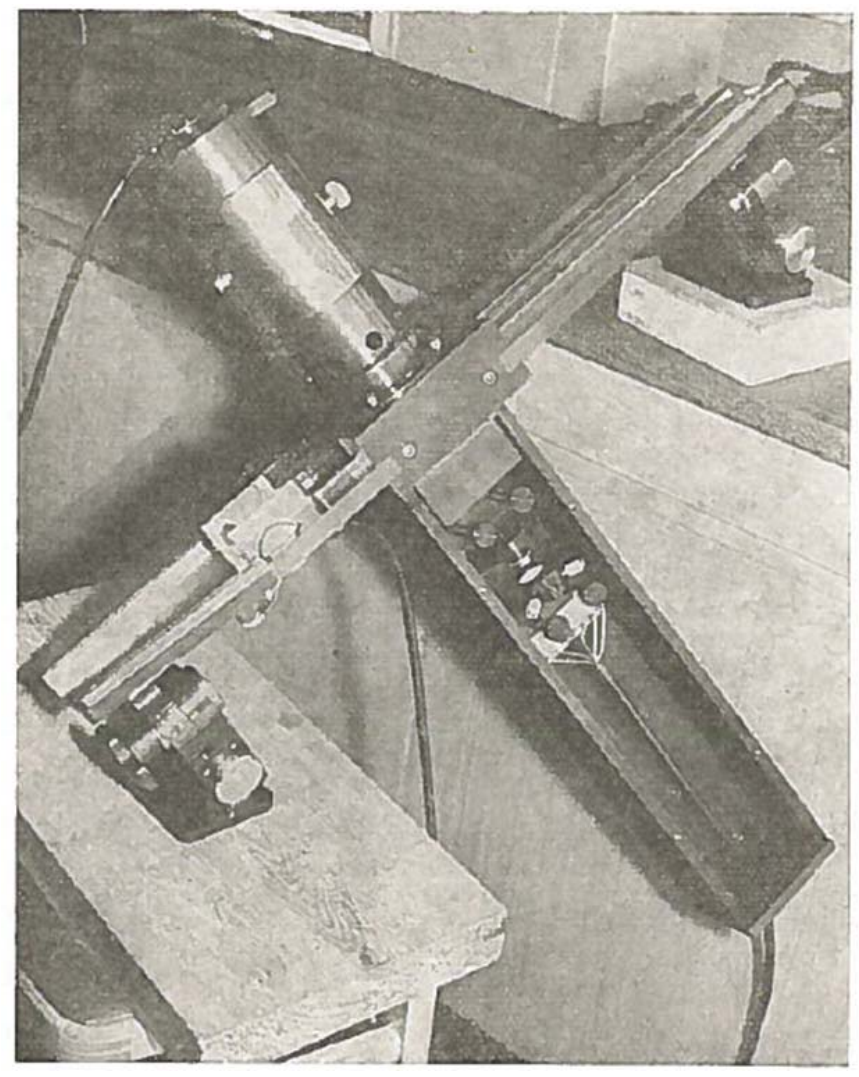

Figure 3. Apparatus for detecting defective coin blanks. 
complex patterns in multicolour print. I doubt if this problem is likely to be solved by traditional scanning methods in which an enormous amount of information is generated in the scan and then compared with a reference standard. It is more likely to be an area of opportunity for techniques using image transformation such as holography.

\section{THE CHANGING APPROACH TO INDUSTRIAL INSTRUMENTATION}

Measurement technology for use in industry can no longer be treated as a specialisation separable from the situation in which it is utilised. It has become a vital and interwoven constituent in the overall technology of operation and control of an industrial manufacturing process. This has considerable repercussion on the activities of an organisation engaged on instrument development and manufacture and on the training of the instrument technologist.

The situation one sees developing is this. The manufacturing and processing industries, as users of instruments, will employ increasing numbers of control engineers. These engineers will concern themselves with improving the control of operation of the processes in their factory so as to improve the efficiency of operation of tile production system as a whole. They will also influence the design and specification of the plant installed to make it inherently more controllable. These control engineers will thus work closely with process technologists, production engineers and plant designers. We also see evidence now of management structure having to be changed in order to permit the fullest utilisation of computers for improved production organisation.

It is to the control engineer that the instrument developer will look for advice on the potential usefulness of a new device. I believe the control engineer will act as a vital link between the instrument maker and industrial user. It is due to the too frequent absence of this link that the enthusiastic instrument developer has often been misguided in the past with consequent misplacement of his inventive abilities and the failure of instrument designs to suit the conditions of use.

At present very few user industries employ control engineers and this has made it necessary for instrument manufacturers to extend their activities into control engineering and systems design. To do this they have had to learn much of the business and technology of their customers' industries so that they can offer viable control systems. They have managed to do this for large customer industries, such as steel, chemicals, paper and such like but it is costly for them and particularly difficult to finance as the profit margins on instrument manufacture are modest. The situation is even more difficult when related to the diverse range of smaller unit industries which may in total offer a large potential market but individually offer only small markets for instruments. For these industries there is a need for cooperative work on the development of control technology specific to them. Thus, one expects the set up of automation research and development organisations, oriented to the interests of specific potential user industries such as textiles, ceramics, plastics, timber, light engineering etc. Within these organisations the special instrument development required to implement control systems will be carried out as part of an activity which encompasses systems engineering and process control engineering. As time progresses these organisations will infuse into their industries control engineers and a philosophy of the significance of control. When that is achieved the job of the industrial instrument manufacturers will be greatly eased. They will be able to devote their research and development resources to the development of the next generation of instruments rather than having to devote it to educating their potential customers in the significance of control and to solving their application engineering problems for them.

\section{REFERENCES}

[1] S.S. Carlisle, Getting Automation Applied, Instrument Practice, July 1965.

[2] R.G. Parish, P. Wade, D.A. Watkin, Application of computers and automation techniques to biscuit manufacture, SIRA Confidential research report R339, 1965.

[3] P. Wade, D.A. Watkin, Development of some instrumentation for monitoring the production of semi-sweet biscuits, Food Trade Review, April 1966, p. 48.

[4] P.M. Knowlson, Instrumentation for resistance welding, British Welding Journal Supplement, April 1965, p. 183.

[5] Institution of Production Engineers Journal, volume 43, No. 3, March 1967. 